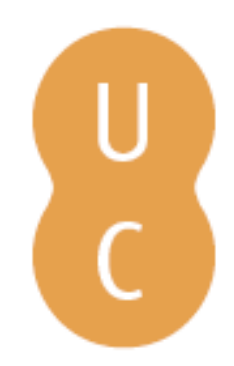

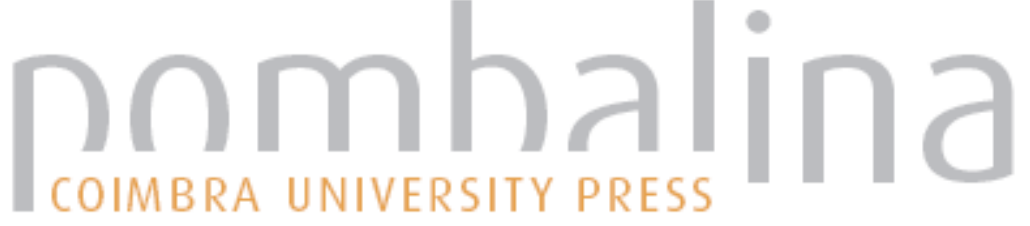

\section{Las traducciones de Gil Vicente al español}

Autor(es): $\quad$ Calderón Calderón, Manuel

Publicado por: Imprensa da Universidade de Coimbra

URL

persistente: URI:http://hdl.handle.net/10316.2/47474

DOI: $\quad$ DOI:https://doi.org/10.14195/978-989-26-1548-6_12

Accessed : $\quad$ 26-Apr-2023 12:04:46

A navegação consulta e descarregamento dos títulos inseridos nas Bibliotecas Digitais UC Digitalis, UC Pombalina e UC Impactum, pressupõem a aceitação plena e sem reservas dos Termos e Condições de Uso destas Bibliotecas Digitais, disponíveis em https://digitalis.uc.pt/pt-pt/termos.

Conforme exposto nos referidos Termos e Condições de Uso, o descarregamento de títulos de acesso restrito requer uma licença válida de autorização devendo o utilizador aceder ao(s) documento(s) a partir de um endereço de IP da instituição detentora da supramencionada licença.

Ao utilizador é apenas permitido o descarregamento para uso pessoal, pelo que o emprego do(s) título(s) descarregado(s) para outro fim, designadamente comercial, carece de autorização do respetivo autor ou editor da obra.

Na medida em que todas as obras da UC Digitalis se encontram protegidas pelo Código do Direito de Autor e Direitos Conexos e demais legislação aplicável, toda a cópia, parcial ou total, deste documento, nos casos em que é legalmente admitida, deverá conter ou fazer-se acompanhar por este aviso. 

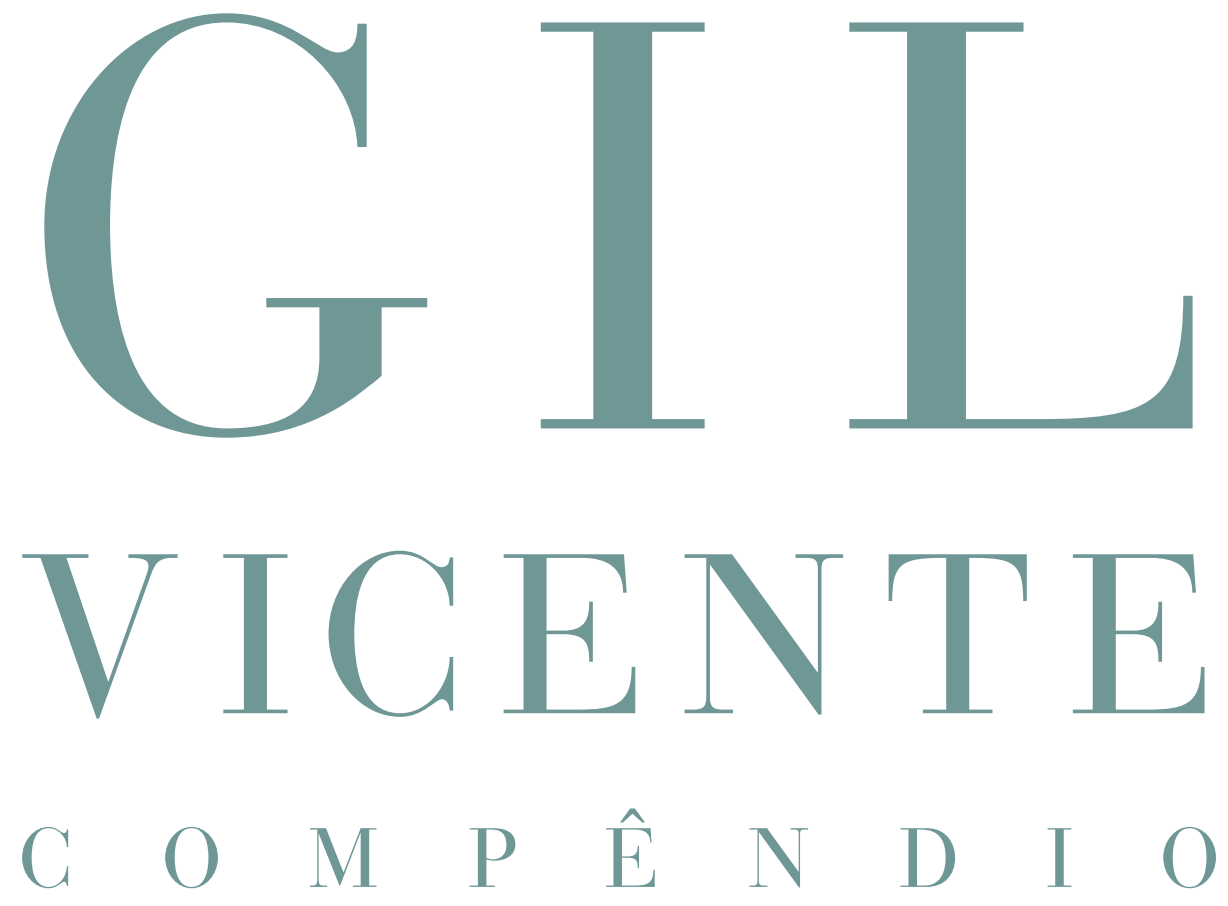

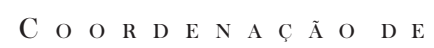

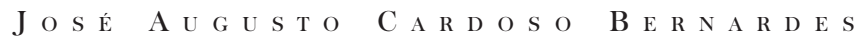

E J O S É C A M Õ E S

CoimbraCompanions

IVPRENSA DA UNIVERSIDADE DE COIMBRA

COIMBRA UNIVERSITY PRESS

IMPRENSA NACIONAL 
XII

\title{
Las traducciones de Gil Vicente al español
}

\author{
Manuel Calderón Calderón
}

Centro de Estudos de Teatro

UNIVERSIDADE DE LISBOA 
(Página deixada propositadamente em branco) 
Aparte de las versiones castellanas de la Barca do Inferno, de 1534 y 1539, sólo se han traducido al español quince obras de Gil Vicente (el Auto da Índia dos veces) y en fechas muy recientes:

Auto da India de Gil Vicente, traducción de María Josefa Postigo Aldeamil y Denis M. Canellas de Castro Duarte, Universidad Complutense, Madrid, 1984, [23 pp.].

Lamento de María la Parda, versión libre y epílogo de Adolfo Castañón; ilustraciones de Roberto Rébora, Aldus, México, 2000, 95 pp.

Autos de las Barcas. Auto de la Barca del Infierno. Auto de la Barca del Purgatorio. Auto de la Barca de la Gloria. Auto de la Feria, introducción, traducción y notas de Andrés-José Pociña López, Universidad de Alcalá, Madrid, 2002, 147 pp.

Gil Vicente, Farsas, introducción, traducción y notas de Manuel Calderón, Ediciones Antígona, Madrid, 2008, 433 pp. [contiene: Farsa de la India, ¿Quién da salvado? El viejo de la huerta, Inés Pereira, Los físicos, El juez de Beira, La fiesta, El clérigo de Beira, Los almocrebes, Romería de los agraviados].

Las cuatro traducciones tienen extensión, metodología y objetivos distintos. La primera de ellas numera los versos y está precedida de una 
reproducción, en dieciseisavo, del facsímil del Auto da Índia, según la Copilaçam de 1562. Los traductores advierten en la presentación que su "traducción es tan sólo un instrumento de acercamiento al texto para su mejor comprensión por parte del lector español» y que «aunque hayamos intentado, en la medida de lo posible, respetar rimas o encontrar otras nuevas, no podemos considerar esta versión definitiva». No obstante, es una traducción muy correcta y ceñida al texto vicentino, casi sin erratas. Comparándola con la del cuarto volumen citado, destaca la traducción atinada del v. 395 (frente a la mía, claramente errónea) y otros tres lugares cuyo sentido hemos interpretado de manera distinta:

\begin{tabular}{|c|c|c|c|}
\hline Verso & Copilaçam 1562 & $\begin{array}{l}\text { María Josefa Postigo } \\
\text { Aldeamil y Denis M. } \\
\text { Canellas de Castro Duarte }\end{array}$ & Manuel Calderón \\
\hline 382 & $\begin{array}{l}\text { quero fiar e cantar } \\
\text { segura de o nunca ver }\end{array}$ & $\begin{array}{l}\text { quiero hilar y cantar, } \\
\text { segura de nunca verlo }\end{array}$ & $\begin{array}{l}\text { quiero fiarme y cantar } \\
\text { para no volverlo a ver }\end{array}$ \\
\hline 460 & $\begin{array}{l}\text { Fomos na volta do } \\
\text { mar }\end{array}$ & Nos bicimos a la mar & $\begin{array}{l}\text { A la deriva flotamos } \\
\text { [porque tres versos antes dice } \\
\text { que pasaron tres días en } \\
\text { medio de una tormenta] }\end{array}$ \\
\hline 479 & $\begin{array}{l}\text { esta camisa que trago } \\
\text { em vossa dita a vesti } \\
\text { porque vinha bom } \\
\text { mandado }\end{array}$ & $\begin{array}{l}\text { y esta camisa que llevo } \\
\text { en vuestra dicha vestí } \\
\text { ya veis, como está } \\
\text { mandado }\end{array}$ & $\begin{array}{l}\text { Esta camisa que llevo } \\
\text { al vuestro gusto mudé } \\
\text { por el buen mandado nuevo } \\
\text { [la buena nueva que esperaba] }\end{array}$ \\
\hline
\end{tabular}

Traducen literalmente, en cambio, el v. 279 (el vino de las estrellas) y se echa a faltar un mínimo aparato de notas culturales; porque, aunque Postigo y Duarte explican los topónimos, no hacen lo mismo con los personajes históricos (vv. 19 y 367) ni con la relación que hay entre ciertos motivos del auto y las citas bíblicas (vv. 37-38, 40, 320, 322); y tampoco comentan las incoherencias entre el tiempo representado o histórico y el tiempo de la representación (vv. 366-367) ni los refranes (vv. 41-42, 43-44, 217 y 285-286; aunque el del v. 23 lo explican traduciéndolo por el sentido y no por su equivalente castellano).

El Lamento de María la Parda es una traducción libre hecha, según su traductor, "omitiendo o adaptando algunos nombres propios o circunstancias locales» y "siguiendo cierto ritmo imaginativo». A lo que añade: «no es faena de filólogo, sino de aficionado amigo» (p. 89). Adolfo Castañón 
se ha basado en las ediciones de Marques Braga (1944) y Paul Teyssier (1995), no en las de 1522, 1562 y 1586; por lo que afirma, erróneamente, que Luis Vicente "omitió este texto en la edición de las obras que hizo de su padre» (p. 90) e interpreta la acotación del v. 171+ como parte del parlamento de Branca Leda.

El traductor divide el texto en tres secciones, que titula "Presentación, Via crucis y Testamento», ya que parte de una doble interpretación socio-histórica (hambruna de 1521-1522) y carnavalesca de la obra. Trae el texto fuente en las páginas pares y la traducción en las impares, pero no puntúa la traducción ni numera los versos y, a veces, no separa las estrofas del texto fuente ni en la traducción (en la que, ocasionalmente, añade un verso a la estrofa).

Llama la atención que, en contraste con el cuidado del soporte (tipo de papel, encuadernación e ilustraciones), los textos contengan tantas erratas (cito por la ed. de José Camões de As Obras de Gil Vicente) en la didascalia inicial y en los vv. 115, 176, 213 (repetido en la traducción), 231 (omitido en la traducción), 239, 252, 261, 266, 282, 293 (falta en la traducción, aunque puede ser deliberadamente), 326, 330 (ha saltado de su lugar en la traducción al texto fuente, entre los vv. 343 y 344), 338, 344 y 364.

En cuanto al carácter libre de la traducción, acaso pudiera explicar versiones como la del v. 207, pero no la de los vv. 324-326:

\begin{tabular}{|c|c|c|c|}
\hline Verso & $\begin{array}{l}\text { Pliego de } 1522 \\
\text { Copilaçam } 1562\end{array}$ & Adolfo Castañón & Propuesta de traducción \\
\hline 207 & $\begin{array}{l}\text { que trago já los olbos } \\
\text { fora } \\
\text { como rola d'anegaça }\end{array}$ & $\begin{array}{l}\text { mis ojos se desorbitan } \\
\text { pupilas de } \\
\text { espantapájaros }\end{array}$ & como tórtola estrangulada \\
\hline $324-326$ & $\begin{array}{l}\text { Item mais me prometi } \\
\text { nua à Pedra } \\
\text { d'Estrema } \\
\text { quando eu tive a } \\
\text { apostema }\end{array}$ & $\begin{array}{l}\text { También a Pedro } \\
\text { d'Estrenu } \\
\text { a quien me prometí } \\
\text { desnuda } \\
\text { cuando tuve un } \\
\text { apostema }\end{array}$ & $\begin{array}{l}\text { Pedra d'Estrema es un } \\
\text { topónimo vinícola (Cf. } \\
\text { Exhortaçam, ed. José } \\
\text { Camões, v. 173; Templo de } \\
\text { Apolo, ibid., v. } 497 \text { y Festa, } \\
\text { ibid., v. 364), no un antropó- } \\
\text { nimo. El sentido de este } \\
\text { pasaje es que María "se curó } \\
\text { con vino", cuyas propiedades } \\
\text { terapéuticas conocían tanto } \\
\text { la Celestina como el primer } \\
\text { amo de Lázaro de Tormes }\end{array}$ \\
\hline
\end{tabular}


Por otro lado, el v. 134 podría interpretarse de manera diferente si entendemos que se refiere a un tiempo próximo al veranillo de San Martín, época de aprovisionamiento para el invierno (con sus celebraciones carnavalescas) e inmediata al Adviento:

\begin{tabular}{llll}
\hline Verso & $\begin{array}{l}\text { Pliego de } 1522 \\
\text { Copilaçam } 1562\end{array}$ & Adolfo Castañón & $\begin{array}{l}\text { Propuesta de } \\
\text { traducción }\end{array}$ \\
\hline $\begin{array}{l}\text { Sangrade-vos Maria } \\
\text { Parda }\end{array}$ & $\begin{array}{l}\text { Desángrate, Parda María } \\
\text { hora es ésta del ayuno }\end{array}$ & $\begin{array}{l}\text { María Parda, a guarir: } \\
\text { que ahora es tiempo de }\end{array}$ \\
e a raia no Avento. & bacalao & atropar \\
& & y de comer raya en \\
& & Adviento. \\
\hline
\end{tabular}

El tercer volumen, con las traducciones de los Autos de las Barcas y Auto de la Feria, es también una traducción libre, aunque no en el mismo sentido que la anterior. Andrés-José Pociña López tampoco pretende reproducir la métrica de los versos vicentinos, aunque afirma que "le ha guiado la fidelidad máxima al texto» y reconoce que en su traducción hay «muchos versos que riman, debido al parecido del portugués y el castellano» (p. 33). Sin embargo, el auto del Purgatorio se titula Barca en la cubierta y en la portada de la traducción, pero Barca y Playa en el índice y en el frontispicio de la p. 67. En la Didascalia inicial del Auto de la Feria se olvida de Dionisio y atribuye los vv. 879-880 a Mateus.

Aparte de las comas mal colocadas y alguna errata esporádica, la primera dificultad con que topa el lector está relacionada con la disposición gráfica de los textos: tanto la ausencia de numeración de los versos como la colocación irregular de los parlamentos, que aparecen sin escalonar cuando forman un solo verso, así como de los nombres de los personajes a la izquierda del diálogo, dificultan la lectura y el cotejo de la traducción con el texto fuente.

En cuanto a la selección y traslado de significantes y significados, esta traducción plantea numerosos problemas. Pociña parte de la ed. de Lello \& Irmão de 1965. En el caso del Auto del Infierno, no ha tenido en cuenta las diferencias entre los testimonios de 1517, 1562 y 1586 ni ha manejado la Edition critique du premier Auto das Barcas, de I. S. Révah; de lo contrario, habría evitado las siguiente incoherencias: 
XII. LAS TRADUCCIONES DE GIL VICENTE AL ESPAÑOL

\begin{tabular}{|c|c|c|c|}
\hline Verso & Texto fuente & Traduce & $\begin{array}{l}\text { Propuesta de } \\
\text { traducción }\end{array}$ \\
\hline Didascalia & $\begin{array}{l}\text { Joane } \\
\text { Florença }\end{array}$ & $\begin{array}{l}\text { Tonto } \\
\text { [omitido] }\end{array}$ & $\begin{array}{l}\text { Joane } \\
\text { Florença o Florencia }\end{array}$ \\
\hline 19 & $\begin{array}{l}\text { iça }(1517) \\
\operatorname{ciça}^{(1562)}\end{array}$ & ciza & Iza \\
\hline 276 & $\begin{array}{l}\text { biu, caga no sapato(1517) } \\
\text { sapato sapato }(1562)\end{array}$ & $\begin{array}{l}\text { [sigue la lectura de } \\
\text { 1562] }\end{array}$ & [lectura de 1517] \\
\hline 410 & $\begin{array}{l}\text { Mais estás: bem } \\
\text { corregido }^{(1517)} \\
\text { Mas estás bem corregido(1562) }\end{array}$ & $\begin{array}{l}\text { [sigue la lectura de } \\
\text { 1562] }\end{array}$ & [lectura de 1517] \\
\hline 438 & $\begin{array}{l}\text { mais de bomem } \\
\text { denodado(1517) } \\
\text { ou de baram denodado }\end{array}$ & $\begin{array}{l}\text { o de barón } \\
\text { denodado [sigue la } \\
\text { lectura de } 1562 \text { ] }\end{array}$ & $\begin{array}{l}\text { o de hombre } \\
\text { denodado } \\
\text { [lectura de 1517] }\end{array}$ \\
\hline 701 & $\begin{array}{l}\text { [parlamento atribuido al } \\
\text { Corregidor] (1562) }\end{array}$ & $\begin{array}{l}\text { [sigue la lectura de } \\
\text { 1562] }\end{array}$ & $\begin{array}{l}\text { [parlamento atribuido } \\
\text { al Procurador] (1517) }\end{array}$ \\
\hline
\end{tabular}

Podríamos resumir en cinco tipos los problemas que plantea esta traducción:

a) el de los versos que no se atienen al significado del texto fuente

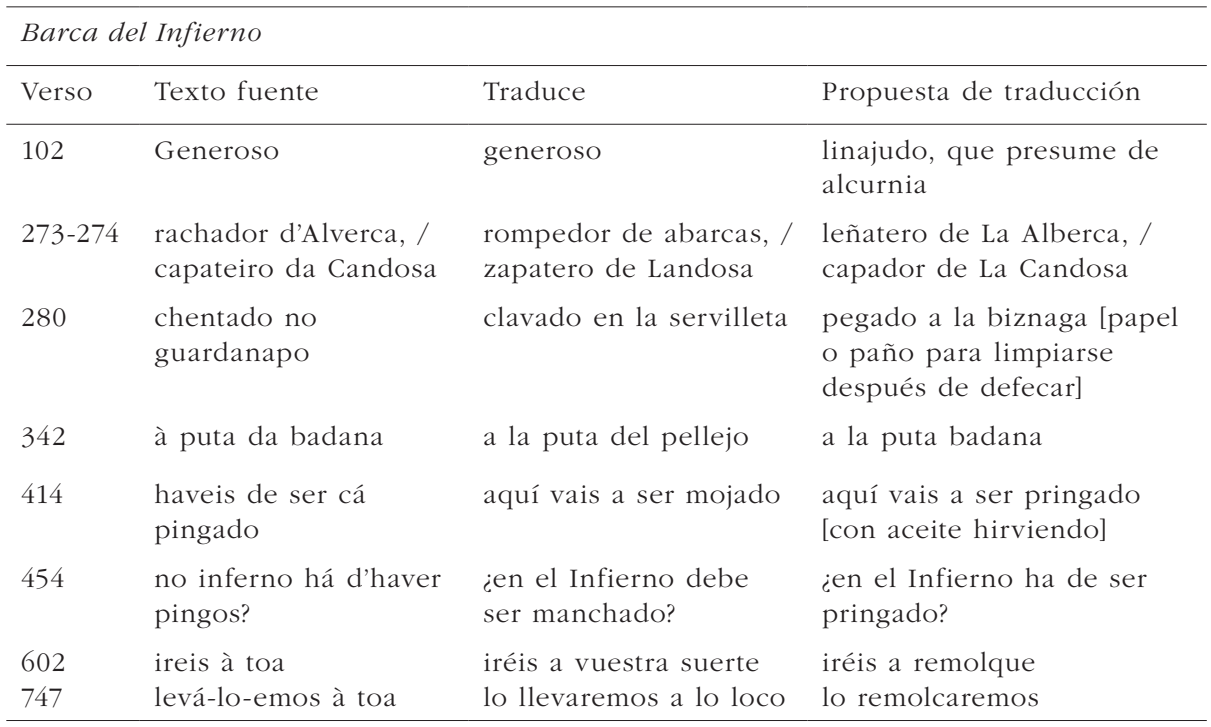

Barca del Purgatorio

\begin{tabular}{llll}
\hline Verso & Texto fuente & Traduce & Propuesta de traducción \\
\hline 11 & Cosida & cocida & cosida \\
80,111 & Barcagem & barcaza & embarque, flete
\end{tabular}




\begin{tabular}{|c|c|c|c|}
\hline 98 & arrumar a caravela & arreglar la caravela & poner a rumbo la caravela \\
\hline 104 & o rio s'encaramelou & el río se acarameló & el río se congeló \\
\hline 144 & um preto & un pleito & un real \\
\hline 157 & $\begin{array}{l}\text { nam dou por isso } \\
\text { um cornado }\end{array}$ & $\begin{array}{l}\text { no doy por eso un } \\
\text { cornado [entiéndase } \\
\text { 'un animal con } \\
\text { cuernos'"] }\end{array}$ & $\begin{array}{l}\text { me importa un comino } \\
\text { [cornado era una moneda de } \\
\text { ínfimo valor: cf. Duardos, ed. } \\
\text { José Camões, v. 938] }\end{array}$ \\
\hline 170 & $\begin{array}{l}\text { que te chante um } \\
\text { par de quedas }\end{array}$ & $\begin{array}{l}\text { que te plante un par } \\
\text { de ruinas }\end{array}$ & $\begin{array}{l}\text { que te dé dos revolcones } \\
\text { [cf. Almocreves, ed. José } \\
\text { Camões, v. 340] }\end{array}$ \\
\hline 252 & Trintairo & trinitario & $\begin{array}{l}\text { treintanario (o trintanario) de } \\
\text { misas en sufragio de un } \\
\text { difunto } \\
\text { [como se aclara en los vv. } \\
255-256 \text {; cf. Reis Magos, ed. } \\
\text { José Camões, v. } 84 ; \text { Farelos, } \\
\text { ed. José Camões, v. 375] }\end{array}$ \\
\hline 515 & Discriçam & descripción & discreción \\
\hline 657 & Espezinhada & empecinada & hollada, humillada \\
\hline $705-706$ & $\begin{array}{l}\text { tirar-vos-am... / dos } \\
\text { olhos a marmeluta }\end{array}$ & $\begin{array}{l}\text { os quitarán... / de los } \\
\text { ojos la mermelada }\end{array}$ & $\begin{array}{l}\text { os han de quitar... / de los } \\
\text { ojos las legañas }\end{array}$ \\
\hline
\end{tabular}

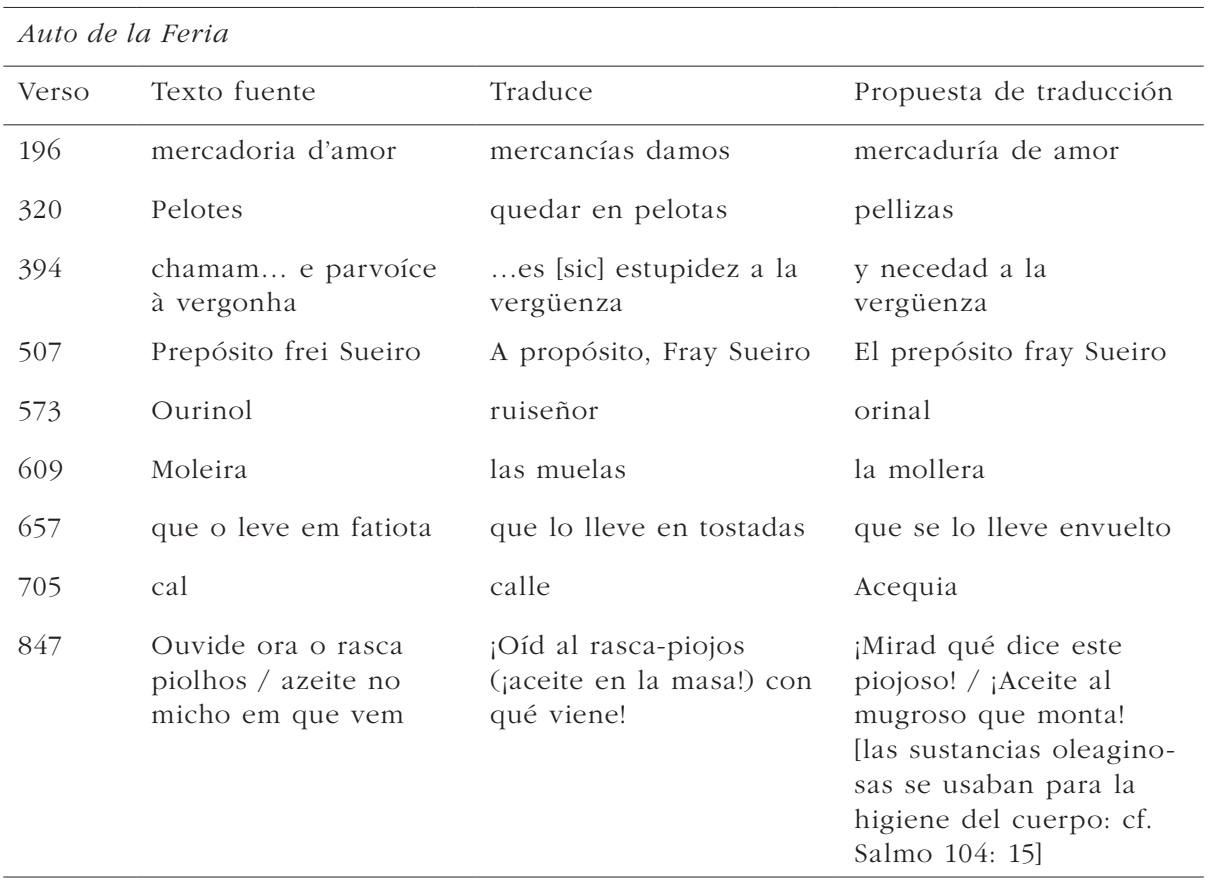


b) las traducciones literales que ocultan el sentido del texto fuente:

\begin{tabular}{|c|c|c|c|}
\hline \multicolumn{4}{|c|}{ Barca del Infierno } \\
\hline Verso & Texto fuente & Traduce & Propuesta de traducción \\
\hline 65 & $\begin{array}{l}\text { do que vós vos } \\
\text { contentastes }\end{array}$ & $\begin{array}{l}\text { de lo que vos os } \\
\text { contentasteis }\end{array}$ & de vuestra disipación \\
\hline 277 & $\begin{array}{l}\text { filho da grande } \\
\text { aleivosa }\end{array}$ & hijo de la gran alevosa & hijo de la gran puta \\
\hline $363-364$ & $\begin{array}{l}\text { escrito estás no } \\
\text { caderno / das ementas } \\
\text { infernais }\end{array}$ & $\begin{array}{l}\text { escrito estás en el } \\
\text { cuaderno / de los } \\
\text { menúes infernales }\end{array}$ & $\begin{array}{l}\text { empadronado estás en } \\
\text { el censo del Infierno }\end{array}$ \\
\hline 421,445 & Dêmos caçada & Demos cazada & $¡ A l$ asalto! \\
\hline 422 & um contra sus & uno contra arriba & un primer quite \\
\hline 423 & un fendente ora, sus & $\begin{array}{l}\text { uno cortante, ahora } \\
\text { arriba }\end{array}$ & ora un tajo mayor, ¡sus! \\
\hline $428-429$ & $\begin{array}{l}\text { Saí co a espada } \\
\text { rasgada / e que fique } \\
\text { anteparada }\end{array}$ & $\begin{array}{l}\text { Salid con la espada } \\
\text { rasgada, / y que quede } \\
\text { reparada }\end{array}$ & $\begin{array}{l}\text { Salid con la espada } \\
\text { abierta / y manteniendo } \\
\text { la guardia }\end{array}$ \\
\hline 443 & $\begin{array}{l}\text { Oh que valentes } \\
\text { levadas! }\end{array}$ & $\begin{array}{l}\text { ¡Oh, qué valientes } \\
\text { levadas! }\end{array}$ & $\begin{array}{l}\text { ¡Oh, qué valientes } \\
\text { estocadas! }\end{array}$ \\
\hline 545 & $\begin{array}{l}\text { Nam cures } \\
\text { d'emportunar }\end{array}$ & No pienses importunar & Deja ya de importunar \\
\hline 608 & $\begin{array}{l}\text { quantos feitos que } \\
\text { trazeis }\end{array}$ & $\begin{array}{l}\text { ¡cuántos hechos que } \\
\text { traéis! }\end{array}$ & $\begin{array}{l}\text { ¡cuántos autos (o } \\
\text { procesos) traéis! }\end{array}$ \\
\hline 656 & eram lá percalços seus & $\begin{array}{l}\text { eran sólo percances } \\
\text { suyos }\end{array}$ & $\begin{array}{l}\text { eran propinas (o extras) } \\
\text { que ella sacaba }\end{array}$ \\
\hline 667 & $\begin{array}{l}\text { os direitos estam } \\
\text { quedos / si aliquid } \\
\text { tradidistis }\end{array}$ & $\begin{array}{l}\text { los derechos están } \\
\text { quietos / si aliquid } \\
\text { tradidistis }\end{array}$ & $\begin{array}{l}\text { la Justicia se imparte / } \\
\text { si has dado algo a } \\
\text { cambio }\end{array}$ \\
\hline 676 & $\begin{array}{l}\text { os mestres de burlas } \\
\text { vistas }\end{array}$ & $\begin{array}{l}\text { los maestros de las } \\
\text { burlas vistas }\end{array}$ & $\begin{array}{l}\text { los prevaricadores } \\
\text { redomados }\end{array}$ \\
\hline 690 & $\begin{array}{l}\text { muito milhor } \\
\text { assombrado }\end{array}$ & mucho mejor asombrado & mucho más afortunado \\
\hline 711 & Ó pragas pera papel & ¡Oh, plagas para papel! & ¡Oh, peste de leguleyos! \\
\hline $807-808$ & $\begin{array}{l}\text { e ora por ele o salteiro } \\
\text { / e o pregam vitatório }\end{array}$ & $\begin{array}{l}\text { y ruega por él el salterio } \\
\text { / y el pregón vitatorio }\end{array}$ & $\begin{array}{l}\text { y para salvarse, reza el } \\
\text { salterio / y pregona el } \\
\text { buen camino } \\
\text { [pues el pregón vitatorio } \\
\text { era el recitado antes de } \\
\text { ejecutar al reo, exhor- } \\
\text { tando a los oyentes a } \\
\text { que evitasen imitar su } \\
\text { conducta] }\end{array}$ \\
\hline
\end{tabular}




\begin{tabular}{|c|c|c|c|}
\hline \multicolumn{4}{|c|}{ Barca del Purgatorio } \\
\hline Verso & Texto fuente & Traduce & Propuesta de traducción \\
\hline 142 & homem de bô retinto & hombre de buen retinto & hombre de gran tino \\
\hline 145 & Marcos & Marcos & hitos, mojones \\
\hline 227 & $\begin{array}{l}\text { bens... que te sejam } \\
\text { acá guiantes }\end{array}$ & que te sean acá guiantes & que te guíen hasta aquí \\
\hline 243 & nam me dezimei? & ¿no me diezmé? & ¿no pagué el diezmo? \\
\hline 254 & a Gil fiz todo repairo & a Gil todo reparo & a Gil ya desagravié \\
\hline 297 & Vedes outro perrexil & ¡Veis otro perejil! & ¡Mira otro repulido! \\
\hline $321-323$ & $\begin{array}{l}\text { Ora comede-la que vos } \\
\text { preste / ui e que gaio } \\
\text { é ora este / de ribeira }\end{array}$ & $\begin{array}{l}\text { pues comedla, y que os } \\
\text { siente bien / ¡Huy! ¿y } \\
\text { qué grajo es ahora éste / } \\
\text { de la ribera? }\end{array}$ & $\begin{array}{l}\text { Pues con tu pan te lo } \\
\text { comas / ¡Menudo pájaro } \\
\text { de cuenta / es éste! }\end{array}$ \\
\hline 386 & Manifestada & manifestada & confesada \\
\hline 448 & $\begin{array}{l}\text { deu-me dor de } \\
\text { cotovelo }\end{array}$ & me dio dolor de codo & tuve cuitas amorosas \\
\hline 682 & $\begin{array}{l}\text { lá ia a cepa e a } \\
\text { cepeira }\end{array}$ & $\begin{array}{l}\text { allá iba a la cepa y a la } \\
\text { cepera }\end{array}$ & $\begin{array}{l}\text { allá iba la soga tras el } \\
\text { caldero } \\
\text { [podía perderlo todo] }\end{array}$ \\
\hline 736 & Metal & metal & palo [de la baraja] \\
\hline
\end{tabular}

\begin{tabular}{|c|c|c|c|}
\hline \multicolumn{4}{|c|}{ Auto de la Feria } \\
\hline Verso & Texto fuente & Traduce & Propuesta de traducción \\
\hline 256 & $\begin{array}{l}\text { Falando com salvos } \\
\text { rabos }\end{array}$ & $\begin{array}{l}\text { Hablando con salvos } \\
\text { rabos }\end{array}$ & $\begin{array}{l}\text { Me lo paso por el culo } \\
\text { (literalmente, "hablando } \\
\text { con salvos culos») }\end{array}$ \\
\hline $\begin{array}{l}360, \\
401,406\end{array}$ & Canseira & cansancio & $\begin{array}{l}\text { trabajo, tribulación, } \\
\text { penalidad }\end{array}$ \\
\hline 376 & $\begin{array}{l}\text { o que eu trago no } \\
\text { cuidado }\end{array}$ & $\begin{array}{l}\text { lo que yo traigo en el } \\
\text { cuidado }\end{array}$ & $\begin{array}{l}\text { lo que estoy interesado } \\
\text { en comprar }\end{array}$ \\
\hline 458 & Partido & partido & trato, negocio \\
\hline 483 & $\begin{array}{l}\text { que vejo maus } \\
\text { aparelhos }\end{array}$ & que veo malos aparatos & $\begin{array}{l}\text { que está mal aparejado } \\
\text { [que no lleva buen } \\
\text { camino o pinta mal] }\end{array}$ \\
\hline 734 & e tapados pera a calma & y tapados para la calma & $\begin{array}{l}\text { y de ala ancha para el sol } \\
\text { [port. calma: calor do sol] }\end{array}$ \\
\hline 833 & Vós rosa do amarelo & Vos, rosa del amarillo & Vos, rosa entre lo pálido \\
\hline
\end{tabular}

c) la traducción que no explicita, mediante una nota explicativa, las alusiones y sentidos implícitos (Barca del Infierno: Didascalia y vv. 19, 29-30, 73, 
124, 189, 244, 482, 263, 449, 451, 569, 585, 607, 614, 622, 623, 634, 638, 643, 647, 657-658, 659-660, 661-664, 665, 670, 674, 706, 724, 729, 735, 745, 750, 761, 792-793, 811-812; Barca del Purgatorio: vv. 83, 121, 129, 251, 263-265, 267-268, 434+; Auto de la Feria: vv. 36, 86+, 191-192, 197, 457, 565-566, 695) d) las traducciones imprecisas o forzadas:

\begin{tabular}{|c|c|c|c|}
\hline \multicolumn{4}{|c|}{ Barca del Infierno } \\
\hline Verso & Texto fuente & Traduce & Propuesta de traducción \\
\hline $\begin{array}{l}\text { 199, 615, } \\
649,710, \\
728,789, \\
818,819\end{array}$ & Batel & bajel & batel, bote, esquife, barca \\
\hline 377 & $\begin{array}{l}\text { E nam vos punham lá } \\
\text { grosa? }\end{array}$ & $\begin{array}{l}\text { ¿y no os decían allá } \\
\text { alguna cosa? }\end{array}$ & $\begin{array}{l}\text { ¿y no os pusieron } \\
\text { objeción? }\end{array}$ \\
\hline 414 & $\begin{array}{l}\text { Mantenha Deos esta } \\
\text { coroa }\end{array}$ & $\begin{array}{l}\text { ¡Mantenga Dios esta } \\
\text { corona! }\end{array}$ & ¡Líbreme Dios la coronilla! \\
\hline $455-456$ & $\begin{array}{l}\text { Ah, nam praza a Sam } \\
\text { Domingos / com tanta } \\
\text { descortesia }\end{array}$ & $\begin{array}{l}\text { ¡Ah!, no plazca a } \\
\text { Santo Domingo / con } \\
\text { tanta descortesía }\end{array}$ & $\begin{array}{l}\text { ¡Santo Domingo me valga } \\
\text { / contra tanta villanía! }\end{array}$ \\
\hline 591 & carrapato d'Alcoutim & garrapata de Alcoutim & judía de Alcoutim \\
\hline 666 & $\begin{array}{l}\text { que o dar quebra os } \\
\text { penedos }\end{array}$ & $\begin{array}{l}\text { que el dar quiebra } \\
\text { los peñascos }\end{array}$ & $\begin{array}{l}\text { que dádivas quebrantan } \\
\text { peñas }\end{array}$ \\
\hline
\end{tabular}

\begin{tabular}{|c|c|c|c|}
\hline Verso & Texto fuente & Traduce & Propuesta de traducción \\
\hline 97 & deitar a prancha fora & echar la pasarela fuera & quitar la pasarela \\
\hline 118 & este seram & esta velada & $\begin{array}{l}\text { este remo } \\
\text { [remo es "trabajo grande } \\
\text { y continuado"; seram es } \\
\text { "el trabajo nocturno"] }\end{array}$ \\
\hline 131,660 & eramá & de una puta vez & maldita sea, diantre \\
\hline 134 & $\begin{array}{l}\text { sorrira-me eu } \\
\text { tamalavez }\end{array}$ & me sonreiría tal vez & $\begin{array}{l}\text { hasta me haría gracia } \\
\text { [tamalavez es "un poco»] }\end{array}$ \\
\hline 203 & nem somente & ni solamente & ni siquiera \\
\hline 205 & bradam com ele & berrean con él & $\begin{array}{l}\text { le echan en cara a } \\
\text { gritos }\end{array}$ \\
\hline 228 & ia ao bodo da ermida & $\begin{array}{l}\text { iba a la fiesta de la } \\
\text { ermita }\end{array}$ & $\begin{array}{l}\text { iba a la gallofa de la } \\
\text { ermita }\end{array}$ \\
\hline 230 & $\begin{array}{l}\text { dava esmola aos } \\
\text { andantes }\end{array}$ & $\begin{array}{l}\text { daba limosna a los } \\
\text { viandantes }\end{array}$ & $\begin{array}{l}\text { daba limosna a los } \\
\text { vagabundos }\end{array}$ \\
\hline
\end{tabular}




\begin{tabular}{|c|c|c|c|}
\hline 454 & motrete de pam & mollete de pan & Mendrugo \\
\hline $752-753$ & $\begin{array}{l}\text { tenho saudade / de te } \\
\text { ouvir arrenegar }\end{array}$ & $\begin{array}{l}\text { tengo nostalgia ["palabra } \\
\text { intraducible»] / de oírte } \\
\text { renegar }\end{array}$ & $\begin{array}{l}\text { echo de menos / tus } \\
\text { continuos reniegos }\end{array}$ \\
\hline 756 & Aramá & ¡A la mierda! & ¡Pestes! ¡Maldita sea! \\
\hline \multicolumn{4}{|c|}{ Auto de la Feria } \\
\hline Verso & Texto fuente & Traduce & Propuesta de traducción \\
\hline 280 & $\begin{array}{l}\text { entra a minha } \\
\text { quintalada }\end{array}$ & entra mi tienda pesada & coloco mis mercancías \\
\hline 291 & sages & sabio & prudente \\
\hline 499 & cá em fundo & acá en el fondo & aquí abajo \\
\hline $515-16$ & $\begin{array}{l}\text { Folgo bem / de te vir } \\
\text { aqui achar }\end{array}$ & $\begin{array}{l}\text { Me alegro bien / de } \\
\text { venirte aquí a encontrar }\end{array}$ & $\begin{array}{l}\text { Huelgo mucho / de } \\
\text { verte por aquí }\end{array}$ \\
\hline 537 & $\begin{array}{l}\text { Tens boa molher de } \\
\text { teu }\end{array}$ & $\begin{array}{l}\text { tienes buena mujer para } \\
\text { ti }\end{array}$ & $\begin{array}{l}\text { Por tu parte, tienes } \\
\text { buena mujer }\end{array}$ \\
\hline 617 & qu'elas ambas vem & que ellas ambas vienen & que las dos vienen \\
\hline $669-670$ & $\begin{array}{l}\text { para eu ser arrepelado } \\
\text { / nam havi'eu mais } \\
\text { mester }\end{array}$ & $\begin{array}{l}\text { para yo ser apaleado / } \\
\text { no tenía yo más } \\
\text { menester }\end{array}$ & $\begin{array}{l}\text { para darme repelones / } \\
\text { ella me basta y me } \\
\text { sobra }\end{array}$ \\
\hline 742 & pucarinha & ollita & tarrito \\
\hline 753 & falar por pincéus & hablar por figuras & $\begin{array}{l}\text { hablar remilgado } \\
\text { [por figura tiene otros } \\
\text { sentidos en el teatro } \\
\text { vicentino] }\end{array}$ \\
\hline 793 & $\begin{array}{l}\text { porque creo que a ti } \\
\text { crea }\end{array}$ & $\begin{array}{l}\text { porque creo que a ti } \\
\text { creerá }\end{array}$ & porque a ti te creerá \\
\hline 796 & $\begin{array}{l}\text { mora / junto c'o juiz } \\
\text { d'aldea }\end{array}$ & $\begin{array}{l}\text { mora / junto con el juez } \\
\text { de la aldea }\end{array}$ & $\begin{array}{l}\text { mora / con el juez de la } \\
\text { aldea }\end{array}$ \\
\hline $851-852$ & comer / da vaca & comer de la vaca & comer vaca \\
\hline
\end{tabular}

e) y el uso de expresiones coloquiales anacrónicas o que no traducen el tono del enunciado (Barca del Infierno: vv. 28, 567; Barca del Purgatorio: 289, 350), así como de formas agramaticales en español (conjugación del verbo morir)

El último volumen reúne varias piezas que comparten un rasgo común: pertenecer al género de la farsa. Bien es verdad que se podrían haber incluido otras y haber acompañado la traducción con la transcripción de los 
textos de la Copilaçam; pero razones de tipo editorial han limitado la extensión del volumen. Lamentablemente, además de las erratas (pp. 10, 17, 22, 28, 40, 45, 48, 107, 111, 230, 232), también se perdió el índice en el proceso de maquetación.

Al traducir estas Farsas, opté por mantener la estructura métrica de los textos vicentinos y hacer una traducción filológica, en lugar de modernizar la traducción y los textos castellanos que están en boca de algunos personajes; lo cual resuelve ciertos problemas de coherencia y cohesión, aunque acarrea otros, como veremos.

En primer lugar, he modernizado la fonética consonántica, pero no las vacilaciones vocálicas ni los lusismos. De lo contrario, la traducción disonaría con el bilingüismo aportuguesado de los textos vicentinos, el cual remite a un marco semiótico más amplio que el puramente verbal. Así, en ¿Quién da salvado? Ordoño habla en un castellano lleno de lusismos, que mantengo (salvo en el v. 2) como en el resto de los autos (el vocablo lunar, en Físicos, v. 676 de la ensalada en castellano original, que reaparece en Agraviados, vv. 1071 y 1076).

En segundo lugar, he optado por una traducción interlingual del portugués del siglo XVI al castellano de la misma época, por dos razones: porque la traducción intralingual del castellano quinientista al español del siglo xxi no encajaría con los textos castellanos de la Copilaçam y porque al traducir he tenido en cuenta el contexto o hábitos de lectura contemporáneos en ambas lenguas. La familiaridad con los usos y registros de habla típicos (es decir, convencionales) de los personajes de los autos y farsas del Renacimiento obliga a que sólo muy esporádicamente recurra, por mor de la rima, a términos diacrónicamente posteriores a la época de Gil Vicente (sansirolé x sandeu en Farelos, v. 17). Traduzco también las variantes más significativas cuando existen dos versiones de un mismo texto, debidas a la intervención de la censura (1562 y 1586).

Por la misma razón, he traducido el guiné (variante diastrática del portugués hablado por los esclavos africanos) a su equivalente lengua de negro (la misma variante de habla en el castellano de la época), ya que ambas forman parte de un código, a la vez, verbal y semiótico del que también forman parte las acotaciones implícitas, la polifonía o variantes de habla 
(que, junto al bilingüismo, expresan ideologías e intereses divergentes: cortesano-villano, hombre-mujer, sagrado-profano), la intertextualidad, la música y hasta la iconografía, inadvertidas para al receptor actual sin las notas que acompañan a la traducción.

Si a a lo anterior unimos la necesidad de hacer explícitas mediante notas las informaciones implícitas de tipo léxico, literario-musical, paremiológico, histórico y religioso, el inconveniente de mi traducción es que presente tantas dificultades para un lector actual relativamente culto como el texto portugués para el mismo tipo de lector lusohablante.

En cuanto a la traducción intersemiótica o del texto espectacular, me he limitado a transcribir las didascalias y acotaciones que aparecen de forma explícita en la Copilaçam. Sin embargo, habría que explicar cuál es la semiótica teatral implícita. Sirvan de ejemplo los valores sociales y morales implícitos en el uso de las variantes diatópicas y diafásicas del portugués, del castellano y de otras lenguas, que en este teatro sirven para marcar la distancia jerárquica, étnica y estética ente unos personajes y otros. O la referencia, recurrente en las didascalias, a que los textos se representaban "por figuras" (y "por contemplaçam» añade la didascalia de la Barca do Inferno de 1517), es decir, por personajes que pueden representar al autor, como da a entender el nombre común (Gil) de todos los que aparecen en la Barca (o Praia) Purgatória, caracterizados por unos actores con unas competencias dramáticas, relacionadas con su conocimiento del mundo y la cultura heredada, llena de presencias y no de ideas o abstractas alegorías, que es a lo que nosotros, espectadores o lectores posterasmistas, postilustrados, postcomtianos y postnietzschanos tendemos a convertirlas.

En definitiva, si partimos, como Steiner, de la idea de que la traducción no es una simple actividad lingüística ni teórica, sino un acto del entendimiento (la curiosidad por el conocimiento del mundo y, en el caso de Gil Vicente, pretérito y cada vez más ajeno), tendremos que decidir cuál será el grado de desplazamiento hermenéutico que demos a nuestra traducción. Los textos vicentinos, por su idiosincrasia, obligan al traductor a la incorporación o importación (más allá de la selección) de formas y significados de la lengua de partida a la lengua de llegada. Aunque dada la distancia temporal entre los signos y referentes del siglo XVI y los del lector actual, eso no basta y 
necesitamos acompañar la traducción con un escueto pero suficiente aparato de notas, ya que la fidelidad del resultado no debe ser tanto al texto de llegada (como querían Fray Luis de León y Pedro Simón Abril) ni al texto de partida (como a partir del Romanticismo), sino a la relación del lector con el texto verbal y espectacular; texto que habrá de tener esa «extrañeza vital» de la que habla Steiner y que, en casos como el de Gil Vicente, no puede ir destinada a un lector pasivo, desapercibido ni espontáneo.

\section{BIBLIOGRAFÍA}

Bobes Naves, M. C. (1997), Semiología de la obra dramática, Arco Libros, Madrid.

Bustos Tovar, José Jesús de (2006), «Lengua común y lengua del personaje en la transición del siglo XV al XVI», en C. Baranda y E. Vian (eds.), El personaje literario y su lengua, Universidad Complutense de Madrid — Instituto Universitario Menéndez Pidal, Madrid.

Ingarden, Roman (1997), "Las funciones del lenguaje en el teatro», en M. C. Bobes Naves, Teoría del teatro, Arco Libros, Madrid.

Jakobson, Roman (1984), "Los aspectos lingüísticos de la traducción», en Ensayos de lingüística general, Ariel, Barcelona.

Steiner, George (1995), Después de Babel. Aspectos del lenguaje y la traducción, Fondo de Cultura Económica, Madrid.

Santoyo, J. C. (1987), Teoría y crítica de la traducción. Antología, Universidad Autónoma, Barcelona. 